\title{
Looking for Something New: The Provision of Popular Music Studies Degrees in the UK
}

\author{
Martin Cloonan and Lauren Hulstedt \\ University of Glasgow \\ M.Cloonan@music.gla.ac.uk; Ihulstedt@gmail.com
}

\begin{abstract}
This article reports the findings of some commissioned research, which was conducted by the authors in 2012. The research sought to examine the extent of Popular Music Studies (PMS) undergraduate programmes in the United Kingdom, determine their key differences, report the findings and make recommendations to the funders about its future policies for PMS practitioners. We report our findings and the implications for PMS practitioners.
\end{abstract}

\section{Introduction}

In February 2012 we were commissioned by the UK's Higher Education Academy (HEA) to map the extent of Popular Music Studies undergraduate programmes in the United Kingdom. This presented a number of definitional and methodological problems, which we outline below. Our main finding was that, in the UK, PMS is doubly new - it is a new topic taught primarily in "new" (post 1992) universities and other higher education institutions. This "newness" presents its practitioners with a number of problems, which we also highlight. We begin the article by outlining the HEA's role and their commissioning of our work. We then move on to discuss our methodology, research and findings. We end by speculating on the implications of our research for PMS more widely. However, we begin with our funders.

\section{The Higher Education Academy}

The Higher Education Academy (HEA) is funded by the UK's four higher education funding bodies (in England, Northern Ireland, Scotland and Wales) and "champions excellent learning and teaching in higher education" (Higher Education Academy, 2013: web source). The HEA has been established as part of broader attempts to enhance the quality of teaching within UK higher education and it encourages staff within the sector to reflect upon their teaching and strive to improve it. It divides its work into four broad areas of Arts and Humanities; Health Sciences; Science, Technology, Engineering and Mathematics; and Social Sciences. These are further subdivided into 24 subject areas, one of which covers Dance, Drama and Music, and in early 2012 discussions within this subject group led the HEA to commission research into the teaching of popular music within undergraduate degrees across the UK.

The tender for this research was announced in February 2012 and we made a successful bid for the work. Following commission by the HEA, the work was carried 
out in March and April and a final report submitted to the HEA in May. In essence we provided a snapshot of issues facing UK PMS practitioners at a particular point in time. The research was constrained by time, finance and - perhaps most importantly of all the amount of PMS practitioners with whom we were able to interact. Nevertheless we contend that the findings of the research have implications that go beyond the remit of our funders and in many way ways reach to the heart of what PMS practitioners within the International Association for the Study of Popular Music (IASPM) should aspire to the provision of the highest quality courses informed by the best facilities and up to date theory. As will be shown, the results suggest that the study of Popular Music in the UK in 2012 is a multi-faceted field, which faces a number of important issues, such as status as a relatively new area of academic study and its cross-disciplinary nature. As will become apparent, one result of this is some confusion about what PMS actually is, let alone how it should be taught.

The research aimed to provide a map of current provision of Popular Music Studies (PMS) within undergraduate UK Higher Education (HE). As agreed with the HEA, it investigated the design and delivery of theory and analysis in $\mathrm{HE}$ popular music undergraduate programmes and explored the various approaches in order to, firstly, identify these; secondly, to clarify where and how they might differ; thirdly, to provide a guide to inform current and future practice and practitioners.

\section{Research Design}

In consultation with the funders we designed a three-pronged methodology. This consisted of (i) a map of provision; (ii) an online questionnaire for PMS providers; and (iii) interviews with four practitioners. We now deal with each in turn. ${ }^{1}$

The first issue we confronted was how to determine the extent of PMS programmes across the UK. Our methodology here was to use information provided to potential applicants on the UK's University Central Admission Service (UCAS) website (www.ucas.ac.uk/) and drilling down after searching for music programmes. However, this process revealed an immediate problem, which was to feature throughout the research: that of nomenclature. While the tender document had referred to "HE popular music", we were aware that Popular Music degree programmes could entail a variety of titles including, for example, Commercial Music and Music Production. Overall, the titles of Popular Music degree programmes vary across the UK and so the first problem was to decide which programmes we were going to include.

We were also aware that the timescale for the research meant that we could not spend too long identifying every single popular music course (as opposed to full degree programme) in the UK. For example, we knew that there are some popular music courses, which are part of larger programmes (within and beyond Music), but limited our research to entire degree programmes orientated towards Popular Music. We also made strategic decisions to exclude Jazz (the subject of six dedicated degree programmes in the UK) and music technology. In both cases, the issue was one of focusing the research. Jazz was omitted because of a belief that the majority of PMS programmes would concentrate on music from around the mid-1950s onwards. Music Technology (variants of which are taught in over fifty HEls across the UK) had the potential to distort an emphasis on popular music. We accept that such demarcations are contestable, but were driven by a need to focus a quick piece of research and by the requirements of our funder. Having excluded these areas, we identified the following titles for degrees taught in at least two UK Higher Education Institutions (HEls): Popular Music, Popular Music Performance, Commercial Music, Music Business, Music (Industry) Management, (Popular/Commercial) Music Production. 
There are numerous variations on such titles and a number of miscellaneous titles (e.g. Music Journalism and Broadcasting).

Our task was further complicated by the problematic status of both "degree" and Higher Education Institution (HEI) within the UK. To simplify matters a little, traditionally UK undergraduate degrees were three-year full time programmes ${ }^{2}$ taught within universities and polytechnics. While most programmes still take this form, since the 1992 Higher and Further Education Act, a number of important reforms have taken place. Polytechnics have generally assumed University status and those post-1992 Universities are generally referred to as "new" universities. In addition, increasing numbers of higher education programmes can be found within further education colleges, and various institutions have reached reciprocal arrangements whereby institution A's programmes may be taught within institution B or students from institution $B$ may use credit gained there towards a degree in institution $A$.

In addition a range of "foundation degrees" - which are less than three years - were included in the research. Such degrees were introduced to serve specific vocational areas and to meet the higher education aspirations of those who are already employed. According to the UK government these degrees are "designed to equip you for a particular area of work - as well as giving you the general skills that are useful in any type of job" (Department for Education and Skills, HMSO, 2007: websource). While universities differ in how they use foundation degrees, they often mix initial part-time study with a requirement to move to a year's full time study in order to progress to a degree with Honours (ibid). ${ }^{3}$ The intricacies of UK HE qualifications are doubtless best left for another time. It suffices to note here that following discussion with the HEA we included Level Five foundation degree programmes within the research, with a total of 13 such programmes being found and included.

To summarise, as an interdisciplinary field of study in a varied field of HE course provision, the simple quest to find the extent to which Popular Music degree programmes are taught within UK Higher Education Institutions is beset by the challenge of defining each of the key terms - "Popular Music", "degree" and "Higher Education Institution". In addition, each part of the four constituent parts of the UK has, to varying degrees, a different system of funding and providing higher education. However, despite these multifaceted issues we believe that our methodology allowed us to identify the main PMS providers and degree programmes across the UK. Using the information on the UCAS website and then drilling down via institutional websites we were able to gather information on degree title, entry requirements and core modules within the identified degree programmes. We were also able to identify key personnel leading such programmes and this information was utilised in the second part of the research.

Secondly, following the identification of Programme Leaders, an online questionnaire was designed. All relevant HEls were contacted via the key personnel whom we had identified and these Programme Leaders were all asked to complete our questionnaire. As with any questionnaire, response rates were largely dependent on the goodwill of those responding. We tried to facilitate this in two ways. First we made it clear that the research was in the interests of those responding, whom we broadly identified as Popular Music Studies Practitioners. Secondly we took the pragmatic decision to design the questionnaire so that it could be completed quickly, hopefully again boosting response rates.

The questionnaire included questions relating to such areas as each programme's approximate annual intake (and whether this was changing), its structure, dissertation work, student placements within the music industries, destinations of students etc. As 
noted above, the HEA's role is to monitor the quality of teaching with UK HE and this necessitates talking to practitioners about their developmental needs. Thus we also asked respondents what the HEA should be doing with regard to Popular Music and if they were interested in joining an HEA network of Popular Music Studies practitioners.

Thirdly, following the completion of the questionnaire four key informants were identified for personal interviews. The intention here was to get a spread of interviewees from across the types of degree and this resulted in one from the pre1992 sector and three from the post-1992. The interviews were semi-structured and allowed for issues to be developed in more depth than the questionnaire allowed. Having explained the methodology, we now move to the outcomes.

\section{Findings}

\section{(i) Mapping Provision}

As just noted, the first stage in the review process was a monitoring of all Popular Music degree programmes in the UK based on information from the UCAS website. Having identified the degrees, further information such as degree title, entrance requirements, and core modules was collated for each of the programmes. We also gathered information about key contact people such as Programme Leaders. ${ }^{4}$ While the problems of nomenclature alluded to earlier should be born in mind, the mapping of provision revealed that Popular Music degrees (including foundation degrees) are taught at forty-seven Higher Education Institutions (HEls) and affiliated providers across the UK. To put this in perspective this is around one in three of all HEls in the UK. As noted above, one division within UK HEls is those which had University status prior to 1992 and those which have achieved it since - the "old" and the "new". Again there is not space to go into detail of this here, but as a rough rule of thumb it is the older institutions that tend to be both the most prestigious and the most researchintensive.

Within the context of UK Higher Education one key (and expected) finding of our research was that PMS provision is dominated by post-1992 institutions. Of the fortyseven providers we identified, twenty-seven are new Universities and thirteen a mixture of University Colleges and further education colleges, often themselves post-dating 1992. Only seven "old" universities (all in England) offer Popular Music degrees - six of these are called variants of Popular Music and one is the University of Southampton's Music and Management Sciences programme. In addition the University of Kent offers a foundation degree in Popular Music Performance via K College, and the University of Essex validates Colchester Institute's Popular Music foundation degree.

he forty-seven institutions provided a total of seventy-six PMS degree programmes. Of these, fifty-two awarded were a BA (Hons), eight a BMus (Hons), one a BSc (Hons), two BA/BSc Joint Honours, and thirteen were foundation degrees. ${ }^{5}$ These have been summarised in table 1.

The second key finding of the mapping exercise was that the majority of PMS programmes have been introduced within the past ten years. Thus within UK HE PMS can be seen as doubly "new"; it is a "new" subject largely taught within "new" universities. It can be seen as a subject area that is struggling to legitimise itself largely while being taught within institutions which may also face the problems of legitimisation common to any enterprise. 
Table 1: Summary of PMS degrees in the UK

\begin{tabular}{|l|c|}
\hline Name of Degree & Number \\
\hline Popular Music & 35 \\
\hline Management (various) & 15 \\
\hline Performance (various) & 6 \\
\hline Commercial Music & 6 \\
\hline Music Industry/Business & 4 \\
\hline Live/Promotion & 3 \\
\hline Production & 3 \\
\hline Miscellaneous & 4 \\
\hline Total & 76 \\
\hline
\end{tabular}

Once the degree programmes were identified, details such as entry requirements, core modules, overall aims, and programme leaders were compiled using each university's programme website as the primary source of information. Perhaps inevitably there was a degree of inconsistency in the details that websites provided. While approximately half offered a programme overview, core modules, entry requirements and additional information in easy-to-find weblinks, this was by no means a universal system. Many programmes only offered basic programme information (and perhaps a few student/staff testimonials), did not clearly identify "core" modules, and neglected to provide specific names or contact information for direct inquiries. Had we been potential students comparing one degree to another in order to make a choice, we would not always have found this to be the easiest of tasks.

Despite such constraints we identified approximately 560 "core" modules across the seventy-three programmes. Our next task was to try and group these into meaningful categories in order to make comparisons and identify trends where appropriate. The time- and resource-limited nature of our study did not permit us to undertake a thorough investigation of each module's content (nor was this information necessarily available) so the research relied on the module titles to indicate the subject matter.

Once again the limitations and problems of nomenclature became a significant limitation. One example of this is the fact that while we were commissioned specifically to identify "Popular Music" as a subject. When compiling module information it became difficult to discern whether "popular" was indeed an important factor in course nomenclature. For example, some core courses specified "Popular Music Practice" while others specified "Contemporary Music Practice". In another example Marketing might be listed simply as such, or more specifically as "Marketing Popular Music" or "Music Marketing". While we do not suggest that such issues are unique to PMS, they clearly add further confusion to a situation within which degree nomenclature is clearly an issue.

In order to better understand the scope of study that is represented by these modules, the course names were grouped into rough categories by subject, following Cloonan's model of musical, vocational (including business studies) and theoretical (Cloonan 2005: 83). These three categories proved a useful starting place for the categorisation of PM modules; in this study, however, the "musical" grouping is renamed "practical" and expanded to include PM production while "theoretical" is renamed "critical". Our categorisations are as follows:

- "Practical" - Performance, musicianship, and songwriting/composition modules; production modules. 
- "Vocational" - business-related courses involving sectors across the music industries; employment in music that is not actual performance.

- "Critical" - courses involving the theory and analysis behind broader concepts in popular music, such as cultural and historical studies.

The mapping showed clearly that current provision of PMS is highly varied. This may be to the benefit of students who have a wide variety of programmes to choose from and may be able to tailor their choices to their goals and interests. However it also raises questions about the extent to which PMS can be viewed as a coherent and unified field of study. Put bluntly, what should a PMS degree consist of?

\section{(ii) The Online Survey}

The second stage in the research was the online questionnaire, which we advertised to all the Programme Leaders that we had identified. The questionnaire was designed in consultation with the HEA and went live on 23 February 2012 with a finishing date of 9 March. We received replies from thirty-one individuals based at twenty-three HEls (of which six were pre-1992) and covering thirty-two programmes. ${ }^{6}$ This equates to a response rate of $49 \%$, with a coverage of $43 \%$ of programmes - both statistically significant response rates. With regard to the thorny issue of nomenclature the survey produced the following results:

Table 2: Name of degree (respondents only)

\begin{tabular}{|l|l|}
\hline Commercial Music & $4(12.5 \%)$ \\
\hline Music Management & $1(3.1 \%)$ \\
\hline Popular Music & $11(34.4 \%)$ \\
\hline Popular Music Performance & $2(6.3 \%)$ \\
\hline Other (please specify) & $14(43.8 \%)$ \\
\hline
\end{tabular}

"Other" was the most popular category and included titles such as Music Promotion; Music and Promotion (our emphasis); Music Journalism; Popular Music Journalism (our emphasis); Live Music; and Music Production and Sound Recording. Overall our respondents can be seen as broadly representative of the broader Programme Leader cohort.

In analysing the data, we were interested in the age of the programme; musicianship; applicant numbers; degree components; work placements; dissertations; student destinations; and student support. First, on the question of when the programmes started, we received twenty-nine responses. The oldest identified dated from 1990 (at the University of Salford); two others began in 1997 and one in 1999. The rest had all been introduced in the last ten years (from 2001-02 on). Of these, eighteen had been introduced since 2006-07. This provides evidence to our claim that Popular Music Studies is an overwhelmingly "new" subject area within UK Higher Education. When combined with the fact that "new" universities dominate provision of PMS within UK HE, there is evidence that PMS is doubly "new" in that it is a "new" subject, the provision of which is largely within "new" HEls. One result of this "newness" - which is reflected later in the survey - is that many PMS practitioners were keen to learn about practice elsewhere and wished the HEA to play a key role in dissemination information about this. We comment further on this below.

Secondly, we inquired into the minimum level of musicianship required for entry to programmes. We received thirty-one responses to this question and it should be noted that respondents were asked to indicate all requirements that applied. This varied a lot 
as some programmes dealt with the Music Industries rather than PMS per se and we did not drill down to differentiate each programme. Overall just over a quarter of respondents reported that advanced performance was needed for admission. Only three respondents cited advanced theory as a prerequisite for entry. Unsurprisingly respondents drew attention to particular attributes needed to study such topics as business and performance and generally looked for relevant background experience in addition to qualifications. Indeed, in many cases respondents reported that having the correct attitude and ambition was more important than technical ability. Differences in the nomenclature of programmes made tracing clear patterns here difficult. However the fact that many programmes do require some evidence of musical ability on behalf of candidates raises interesting questions about how that ability will be developed once they commence their chosen programmes.

Thirdly, the number of applicants granted entry each year ranged from twelve to eighty-five students and varied across the thirty-four programmes our respondents identified. Interestingly, in a context where tuition fees in England are set to roughly treble in 2012-13 to a ceiling of $£ 9,000$ per annum, most respondents reported that the amount of applicants was holding up well.

To address a fourth area of concern with regards degree components, based on the categories we outlined above, respondents were invited to calculate the approximate percentage of their degrees which fell in to the broad categories of "practical", "vocational" and "critical" or "other". Our intention was to tease out what proportions of programmes were broadly devoted to areas such as musicianship, business and (social/cultural) theory. We were always conscious, however, that such divisions are porous and that the categories were likely to overlap. In addition the number of respondents varied across each of the categories, rendering simple statistical analysis problematic. In retrospect this was perhaps one of the least satisfying parts of the survey. Nevertheless, as we will now show, the categorisations did garner some useful findings. For example, a large number of the degree programmes claimed to have a practical element of $40 \%$ or more. In this sense PMS is strongly practice based - with important implications for resources including, it is clear, staff time. The implication here may be that universities considering the provision of PMS degrees with apparent appeal to large numbers of (predominantly) young people also need to take into consideration the resource implications if the programme has a significant practical component.

In addition, despite recent trends towards vocationalism within UK Higher Education far fewer of our respondents claimed that the degree was predominantly vocational. Of twenty-five responses here only two claimed that above $40 \%$ of the programme was vocational. The vast majority (twenty-one out of twenty-five) claimed that between 10 and $33 \%$ of the degree was vocational. However it should be noted here that that our interviewees (see below) often stressed the vocational nature of their programmes and various respondents in the questionnaire spoke of preparing students for work in the music industries, sometimes regardless of whether that work was full time or not. In addition as we again show below, a number of HEls claimed that large percentages of their students went on to work in the music industries. It thus appears that despite programmes generally not having a large vocational component, institutions were imparting vocational skills. 31 respondents replied to a question about what percentage of the degree was analytical, with one claiming $100 \%$. There were clear groupings here of between 20 and $30 \%$ (fifteen of out of thirty-one) and $40-50 \%$ (eleven out of thirtyone). While the terminology here might be value-laden and problematic, it does also 
suggest a potential core for PMS in the sense that it has the potential to open up discussion about what needs to be analysed.

Overall the responses to the categorisations we suggested were perhaps the most problematic part of this project with some concern that the categories were almost arbitrary. As one respondent noted:

The demarcations between these areas are of necessity somewhat blurry: the playing of an instrument can be seen as putting theory to practice, while the refinement of musical skills can also be seen as being vocational in that it may aid employment prospects.

In designing the questionnaire we were aware that the answers to this question were always likely to be somewhat "broad brush" and the categorisations somewhat porous. However from the perspective of our funders, the finding that many programmes had a large practical component suggests that it is here that the HEA might wish to orientate its initial work. In addition it is clear that the categorisations did serve to raise questions about the right balance of courses within PMS degree programmes of whatever sort. It should also be noted that because of the diverse nature of PMS programmes, the questionnaire did not ask specific questions about music theory and analysis as we felt that such a question would not have yielded widespread comment. It appears from our respondents' comments that detailed musical analysis, of the sort associated with traditional, notational, musicological analyses are the domain of relatively few PMS practitioners, primarily located in the "old" universities.

The fifth main issue in the questionnaire relates to the programme provision of placement opportunities, in order to pursue further aspects of vocationalism. Of the thirty-two who replied to this question, seventeen said that they offered placements. While we did not seek detailed information about the nature of the placements, we did ask for further comments. These showed that the term "placement" could - and did encompass a wide range of practices, including being involved in promoting a tour, generally helping out a music industries company and making a public performance. Time spent on placements varied from a few hours through to a specified number of hours and up to two months. The wide range of practices encompassed by the term "placement" meant that it was difficult to make generalised recommendations to the funders. However, one key issue that emerged was the question of who was responsible for organising placements. In at least five instances, students were responsible for arranging placements themselves. Here we were told that this was critical as it encouraged students to develop the confidence and self-assurance necessary to approach people in the music industries, and such attributes would stand them in good stead for potential future work within the music industries.

It comes down to an individual basis, but for the mass of the students, the largest part we'd much rather they found something themselves because they've got to get into the idea of hunting down work, that's just the nature of the industry (Alan Dumbreck, University of West Scotland)

We encourage individuals to seek their own placements in the first instance, because we think that is part of learning to build client relationships (Mark Pulman, University of Huddersfield)

Certainly the question of how placements are identified and organised remains an intriguing one. Our experience at the University of Glasgow makes us aware that this can be a very labour intensive process, again with important resource implications. The provision of placements can be seen both as something which can be a vital part of a programme, but also something not to be undertaken lightly. 
The notion of critical thinking reappeared via a sixth question about whether programmes required dissertation work. The majority of programmes (twenty-four of thirty-two) included dissertations, sometimes as an option. Once again there was range of practices covered by the term "dissertation" with the length of work required varying from 6000 to 15000 words. Nevertheless the widespread use of dissertation work suggests that there is a great deal of research taking place within PMS that is effectively under the radar.

Returning to more vocational issues, we asked about the employment status of former students a year after completing their programme. Of thirty-two responses to this question twenty said that they collated information on this and twelve that they did not. The following indicates the ranges of destinations for PMS students graduating in 2011:

Table 3: Student locations one year after graduation (range of responses)

\begin{tabular}{|l|c|}
\hline Working in the music industries & $25-80 \%$ \\
\hline Working in other industries & $10-60 \%$ \\
\hline Further study & $1-50 \%$ \\
\hline Unemployed & $5-20 \%$ \\
\hline Other & $5-20 \%$ \\
\hline
\end{tabular}

While the categories here are somewhat broad they do provide further food for thought. In particular it should be noted that we did not define "working in the music industries" which might, for example, include working in a bar in a venue. Neither did we specify that such working had to be full time. As is well known, work within the music industries is often characterised by its ad hoc and part-time nature and nine to five full-time jobs are somewhat rare. Nevertheless the fact that some institutions claim that up to $80 \%$ of former students are currently working within the music industries suggests that there are some examples of good practice, which bear further investigation. If substantial numbers of students are undertaking PMS programmes for vocational reasons and some universities have evidence of successfully fulfilling such aspirations, then it is incumbent upon them to share best practice. Meanwhile the fact that a number of programmes were not able to provide information has obvious implications for notions of employability within degree programmes. We note that one of our interviewees suggested that Facebook was the best way to monitor former students. This may appear somewhat flippant, but social networking has obvious potential here.

As noted above, PMS is largely the domain of "new" universities. Such institutions are more likely to attract "non-traditional" students and such students may often require more support than "traditional" students. When asked a seventh question, addressing levels of student support, our respondents replied thus:

Table 4: Levels of student support required

\begin{tabular}{|l|c|c|}
\hline Value & Count & \% \\
\hline Our students, generally, require little additional support. & 5 & 17.9 \\
\hline Our students require some support that we address well. & 7 & 25 \\
\hline Our students require some support that we'd like to address better & 7 & 25 \\
\hline Our students require a great deal of support that we address well. & 7 & 25 \\
\hline $\begin{array}{l}\text { Our students require a great deal of support that we'd like to address } \\
\text { better. }\end{array}$ & 2 & 7.1 \\
\hline
\end{tabular}


Thus around a third of respondents said that they wanted to offer more support. Examination of further comments here revealed that such support fell in to three broad categories. The first concerned the students themselves and could include issues concerned with admitting large numbers of non-traditional students. The second concerned programme content and often focused on dealing with students with a great interest in music but not necessarily the social and cultural theories which surround it. A third response concerned the practical nature of PMS which could put a strain on resources, including - and perhaps especially - staff time. However we do not get the impression of a major lack of support with regards to the particular needs of PMS students.

Finally, respondents were invited to make further comments about the provision of PMS at undergraduate level in UK HE. Eighteen did so, although one commented simply that: "We do not teach popular music 'studies' we teach popular music", again raising the thorny issue of nomenclature. The other seventeen responses saw respondents split over whether more or less cultural and social theory was necessary, whether a certain level of musical proficiency was needed or whether they were adopting or challenging conservatoire models of music education. A few comments help to give the flavour here:

It seems to me that a course called Popular Music means different things depending on the HEI. Managing the expectations of applicants and students effectively is essential when addressing this disparity

It is a difficult subject to teach due to its varied focus and due to the expectations of students. Most students are wholly concerned with the practical side of music making but find that they have to take a degree with more analytical / "academic" work than they expected.

The danger is that it is too narrowly focussed. We are forever trying to extend the range of what constitutes popular music. We have found the input of foreign students, whom have a much more open mind, is a valuable addition.

As a relatively new HE discipline, and the (largely) orally transmitted nature of the music, the teaching is still, I feel, being explored and developed.

\section{Establishing a Network}

It should be borne in mind that this research was commissioned and the needs of the funders were paramount throughout. From a developmental point of view, the HEA was interested in whether PMS practitioners in the UK could see merit in setting up a network of practitioners. Here all 30 of the respondents who answered this question said yes. The enthusiasm with which this suggestion was embraced may not be unrelated to the newness of the PMS programmes, which we noted earlier. In order to flesh out what such a network might achieve, we also asked respondents to list up to three things that they thought the HEA should be doing for PMS practitioners. Somewhat inevitably this elicited a wide range of responses including some outside the HEA's remit. However there were six broad areas, which practitioners felt might be useful - models of best practice, an annual conference of Programme Leaders, the HEA recognising the distinctive nature of PMS, questions of benchmarking and kitemarking, closer ties with the music industries and research. We deal with each in turn.

The first of these concerned the provision of best practice models to be disseminated on the HEA website and/or a magazine. Areas which respondents wanted help with here included the setting of essay questions, lecture themes, Powerpoint presentations and student feedback. Responses included calls for the 
sharing of teaching resources, although we are aware that HEls may claim copyright in the materials, which their staff produce. Nevertheless, the provision of best practice guides in areas such as placements and dissertations may provide a way forward. The second call was for an annual conference for Programme Leaders to disseminate best practice and debate. The third call was, relatedly, for the HEA to play a role in publicising the distinctive nature of PMS which means that it may not fit easily in to the traditional HE model of essays, lectures and seminars. Thus questions of assessment and broader pedagogic practice were to the fore of many minds.

A fourth area concerned the question of benchmarks and kitemarking, which was highlighted by some respondents and included calls for consistency of standards. While this is obviously problematic for an area as diverse (and hard to define) as PMS, ${ }^{7}$ this issue has plagued UK HE for a number of years and the extent to which degrees from different institutions have the same value is a highly contentious issue regarding which initiatives such as the Scottish Credit and Qualification Framework (www.scgf.org.uk/), seek to address. Its use is more familiar within further education than in higher education. Here it raises questions of what PMS graduates can be expected to know or do and thus what PMS is. It may be that in the latter case the guarding of institutional autonomy may limit how far these can be achieved. Nevertheless, it is clear that PMS practitioners wish their work to be broadly comparable with their colleagues in other HEls.

The fifth area is something of a perennial concern and consisted of calls for help in developing more ties with the music industries. This was linked to calls for a "national graduate employability profile". One respondent went so far as to argue that what might help here is a set of shared (broadly liberal) values across both HE and the music industries. However, others noted that forging such links can be a somewhat torturous process. Our own experience is that such links are best forged over an extended period and that there are no shortcuts to the building of mutual respect and confidence. While this may have to be done at institutional - or, probably, individual - level, the formation of an umbrella organisation for the UK music industries in the form of UK Music (www.ukmusic.org) gives scope in principle for HE bodies such as the HEA to develop partnerships.

Despite the questionnaire's focus on teaching, the final, sixth, area in which respondents called for action was in research, where some respondents wanted to establish a research network. This has obvious implications for readers of this journal (especially those based in the UK and Ireland) as, while we did not mention it to respondents, this is a role that IASPM seeks to fulfil. We know that IASPM UK and Ireland has increased its membership in recent years, but it still appears not to be reaching many PMS practitioners. There is obvious work to be done here and in the longer term there may be scope for HEA/IASPM sponsored events that could be to mutual benefit. Overall, the online questionnaire produced a number of responses clustered around provision and the student experience. While the practical implications of the findings are largely a matter for the HEA to pursue, they should also provoke thought amongst reflexive PMS practitioners. It is such people that we turned to next.

\section{(iii) Some Individual Reflections}

Following the completion of the questionnaire we identified four Programme Leaders whom we believed would be particularly informative on PMS provision. Our intention was to get a spread of interviewees from across the types of PMS degrees on offer and we chose three interviewees from the post-1992 sector and one from the pre-1992. Three interviewees from the post-1992 sector- Alan Dumbreck (AD, University of West 
of Scotland), Mark Pulman (MP, University of Huddersfield) and Dave Wibberley (DW, University of East London) all agreed to be interviewed "on the record". The final interviewee $(A B)$ was from the "old" sector and wished to remain anonymous. The interviews were semi-structured and allowed for issues to be developed in more depth than the questionnaire allowed. All interviewees were interviewed in a personal capacity and were not speaking on behalf of their institutions.

We asked each interviewee the following questions: "As a whole, what do you believe Popular Music Studies teachers should be striving to achieve?" Several common themes emerged from this question, with a desire to equip students with the ability to secure employment post-graduation emerging as a key concern:

Ultimately the two aims are to make sure [your programme is] distinct from everyone else and also that you can actually offer something realistic that's likely to get people a job at the end of the day. [...] [Students] should be intellectual and academic on the one hand, but they should also be able to do these jobs as well (AD)

Popular music studies as a whole [...] should be interested in creating versatile graduates, flexible graduates... because it's a daft programme that thinks that they can qualify people as musicians and that they can then expect to get jobs. [...] I think we do students a disservice if we don't awaken them to the versatility and transferability of the skills that they develop along the way $(A B)$

We were also keen to probe interviewees on the sorts of attributes they wanted applicants to possess upon entry (in addition to the necessary academic qualifications). Here all interviewees stressed the importance of individual interviews/auditions - again something that has significant resource implications. The attributes then varied according to the type of PMS programme that was being pursued:

We're looking for students who are performers and wanting to incorporate performance in addition to music promotion activities (MP)

By way of a contrast AB's programme had more of a theoretical approach and did not require any performance experience. Similarly, business-oriented programmes such as DW's often do not require any prior musical knowledge or experience.

As noted earlier, many HEls do not have a formal system in place for tracking students post-graduation and we were keen to find out from our interviewees what their experience was of students' destinations. Of the portion employed in "music and musicrelated industries", our interviews suggested that a significant percentage - AD and MP cited at least $20 \%$ - go into teaching, whether in a traditional academic setting or in instrumental tuition. AB noted that this number is greater for traditional music students who have background in areas such as theory, harmony and notation, and that those PMS students without that sort of background may be at a disadvantage here. Outside of teaching, MP was aware of graduates currently working in freelance/self-employed and others partaking in "quite a diverse range of activities within general entertainment and media, and of course non-music".

In recent years the proliferation of PMS programmes has set a context in which it is increasingly important for individual programmes to enable their graduates to "stand out from the crowd". Our interviewees were therefore asked: "What makes your programme attractive to students?" Here AD commented that:

I like to think the students who come to us, [... do so] because they can see that there's a good chance it will progress their careers, because they'll get access to industryexperienced and academically qualified staff, because they will get access to the facilities that we've got 
Such a comment encapsulates what many PMS practitioners aspire to - boosting graduate employability based on staff imparting a mixture of industry and academic insight within a well-resourced institution.

But such aspirations do not exist in isolation and in many cases PMS practitioners face competition from colleagues at other HEls in the recruitment of students. AD and $A B$ pointed to the importance of being aware of local competition from other institutions, and the need to make their programmes' unique aspects a strength. We thus asked our interviewees what it was that made their programmes distinctive and generally received responses which referred to the particular orientation of the programme, whether this be in terms of a broadly theoretical approach or one which stressed music as a business. However, these should be seen as somewhat broad parameters as interviewees also saw flexibility within programmes and the chance for students to follow their own interests as being vitally important. Placements could also play a role in distinctiveness, with AD reporting a great demand for quite "high level" placement opportunities.

We probed interviewees about what they believed was an appropriate, balanced, mix of practical, theoretical and vocational courses within a programme. As noted above, such categorisations were not universally popular amongst questionnaire respondents. However, interviewees clearly recognised such distinctions and were happy to comment:

The balance definitely errs on the practical and the vocational, but that has to be couched in the degrees of consideration, critical thought. What we don't need to do on this programme - there's room for it on another programme - what we don't need to do on this programme is spend days and days on Adorno (DW)

I'm not sure I would necessarily draw a hard distinction between practical provision and academic provision, because I would hope that within a university environment to be looking at modules where [students] were coming out with practical skills, but developing them in intellectual, scholarly ways (AB)

Related to provision were the main teaching methods that interviewees used. All four indicated that traditional lecture-based modules formed the backbone of their degree programmes. However they were aware that, as MP put it, "a very wide range of teaching methods and pedagogical approaches" was appropriate for a PMS programme. This can include group work, particularly in band/performance modules as well as recording/production; "peer learning" and evaluating; one-on-one tuition, primarily for instrumental modules; performance platforms; and seminars led by postgraduate research teams, usually conducted alongside a more traditional lecture.

Our interviewees also echoed responses found in the questionnaire by backing calls for a network of practitioners; the establishment of best practice guides as well as benchmarks and kitemarks, and the organising of a practitioner's conference. This should be seen in a context where, as $A B$ put it: "English degrees look roughly the same up and down the country, but we are in a discipline that is hugely varied". Once again there appeared to be much to learn and to discuss.

When questioned about the future of PMS and how they would like to see popular music education change in the coming years, respondents produced a range of responses including the following:

l'd like it to stand in its own right, not part of a cultural studies school, cultural theory.

Almost try to lose the word "studies" [...] and [be] a lot less laden with baggage from other disciplines, really (DW) 
Music [business], really over the last $5,10,15$ years, has been in a general decline, yet media and entertainment, I would suggest, is the opposite. So I think there should be more synergy, if you like, involving the context of popular music within the broader entertainment and media industries, and the commercial world (MP)

\section{Conclusion}

We were impressed by the commitment shown by Programme Leaders and while their responses were sometimes disparate, they also provided a number of discussion points. They again showed that PMS provision is highly varied and that its practitioners have a range of ideas, which they are keen to share with other practitioners. The establishment of a practitioner network is an obvious place to begin such a process.

Perhaps the findings here will come as no surprise to readers of this journal. Indeed in many ways the research confirmed many of our pre-existing hunches. It was, however, salutary to find evidence. The most striking insight is the "newness" of PMS as a study subject in the UK. Many programmes are relatively new and often taught in institutions that in their present formation are little more than twenty years old. IASPM was founded over a decade before these institutions were formed but is clearly not a home (hopefully yet) for many within them. As an organisation interested in the study of Popular Music it appears that there is some work to do and it is to be hoped that PMS practitioners increasingly find a home within IASPM.

The general impression gained from the online questionnaire and to some extent the interviews was of PMS practitioners trying to come to terms with what was expected of them. What should they do? How? For whom? What should PMS degrees include? Why? For many PMS practitioners one way of answering such questions is to ask what other people do, and thus we got many respondents wanting to know more about how PMS is taught elsewhere? This cannot be divorced from the question of "newness" and is certainly something that merits further investigation.

Meanwhile as HE has become ever more marketised, it is no surprise that something which appears on the surface to have a ready-made market - in the sense that many (young) people love popular music - should be invested in by a lot of HEls. But the research here belies any sense that the provision of PMS programmes is any sort of soft option. Various routes can be taken but all face common problems of resources, curriculum and vocationalism. Meanwhile the diversity of PMS provision at present makes it hard to see any essential core. However, the commitment shown by Programme Leaders to their students and their area of study shows that whatever else it is, PMS HE cannot simply be reduced to a market relationship.

The UK's divide between "old" and "new" universities was also brought out clearly by the research. It is overwhelmingly the "old" universities that sit at the top of the research league tables, but it is in the "new" universities that the vast majority of PMS teaching takes place. Teaching loads remain higher in the new universities and often restrict the time for research. It is clear that the very term PMS is less familiar in the new universities that are often more focused on teaching than research (although the decision to omit jazz and music technology courses may have had an impact here). In this sense Popular Music or Commercial Music may be a more straightforward nomenclature than PMS.

Initially, our conclusions were mainly for the benefit of our funders, but they do raise serious questions about PMS. Over thirty years after the founding of IASPM our research shows that fundamental questions remain about what the study of Popular Music could and should be. Questions about what PMS actually consists of and what its core might be have resonance well beyond the UK. The same applies to how we 
teach. Our research found that many PMS practitioners in the UK remain somewhat confused about what they should be teaching. Frequent references to finding out what others are doing suggested some nervousness about respondents' own practice. Within the UK, the formation of a network of PMS practitioners will certainly not end such questions. It might, however, provide a fresh focus for them. We certainly hope so.

\section{Endnotes}

${ }^{1}$ The research methodology was also approved by the Ethics Committee of the College of Arts within the University of Glasgow.

${ }^{2}$ Scotland is an exception to this as its undergraduate degree programmes have traditionally been four years long.

${ }^{3}$ For more on foundation degrees see www.ucas.ac.uk/students/choosingcourses/choosingcourse/foundationdegree

${ }^{4}$ It should be noted here that in some cases identifying the key academic responsible for degree programmes was a somewhat time consuming task. It is extremely difficult to identify Programme Leaders for some degrees from University websites. We can only suggest that best practice would include clearly identifying Programme Leaders and providing their details for potential students and other interested parties.

${ }^{5}$ One programme offered the option of a BA or a BA/BSc joint honours degree and was therefore counted twice).

${ }^{6}$ See Appendix $B$ for a list of responding HEls

\section{References}

Cloonan, Martin (2005) What is Popular Music Studies? British Journal of Music Education 22(1): 77-93.

Department for Education and Skills, HMSO (2007) Education and Learning: Qualifications Explained. http://webarchive.nationalarchives.gov.uk/20060213205515/http://direct.gov.uk/en/e ducationandlearning/qualificationsexplained/index.htm Accessed: 31 Jan 2013.

Higher Education Academy (2013) UK, About Us. http://www.heacademy.ac.uk-about Accessed: 31 Jan 2013. 